УДК [316.613.4+316.663]-058.855

ББК $88.611 .9+88.502$

\title{
А.А. Стреленко
}

\section{СТРУКТУРА И СОДЕРЖАНИЕ СОЦИАЛЬНО-ПЕРЦЕПТИВНЫХ ОБРАЗОВ В СОЗНАНИИ ПРИЕМНЫХ МАТЕРЕЙ}

В статье рассматривается роль Я-концепции и определяется ее значение в воспитании детей в биологических и приемных семьях. Целью работы стало определение структурных и содержательных характеристик Я-образов приемных матерей и Ты-образов приемных детей. Основной гипотезой выступило предположение о том, что у приемных матерей структура и содержание Я-образов и образов приемных детей статистически и качественно связаны между собой. В работе приняли участие 78 приемных матерей в возрасте от 29 до 66 лет (M=49,64; $\mathrm{SD}=7,54)$. По результатам проведенного эмпирического исследования были выявлены структурносодержательные особенности в представлениях приемных матерей о самих себе и приемных детях. Были определены различия в социально-перцептивных образах, включающих в себя интеллект социальный, поведенческие, телесные, нейтральные, отрицательные характеристики $(\mathrm{p} \leq 0,05)$, которые включаются в когнитивный, регулятивный и конативный компоненты самосознания. Установлены корреляционные связи между характеристиками образов, отражающими отношение к человеку. Сравнение социально-перцептивных образов по структуре и по содержанию обнаруживает схожесть Я-образов матерей с Ты-образами их приемных детей. Полученные результаты можно объяснить единым механизмом развития социально-перцептивных образов. Приемные матери выбирают ребенка и выстраивают взаимодействие с ним, опираясь не столько на отражение реальных личностных особенностей самого ребенка, сколько на собственные представления о самой себе, на свою Я-концепцию.

Ключевые слова: Я-концепция, Я-образ, Ты-образ, приемные матери, приемный ребенок, приемная семья.

DOI: $10.35634 / 2412-9550-2021-31-4-416-427$

Как известно под Я-концепцией подразумеваются рефлексивную часть личности и ее представление о себе. Сама проблема Я-концепции неоднократно поднималась в зарубежной и отечественной психологии. Так, за прошедшие несколько десятков лет было проведено и проанализировано внушительное количество работ, посвященных Я-концепции детей и взрослых, также ее роли в воспитании детей. Исследованиями в данных областях занимались Б.Г. Ананьев, А.А. Бодалев, А.Н. Леонтьев, В.Н. Мясищев, А.А. Реан, В.Л. Ситников, В.В. Столин, И.И. Чеснокова и др. [13].

В свое время Б.Г. Ананьев отмечал, что образование отношения формирующегося человека к самому себе является наиболее поздним по сравнению с другими свойствами: «Лишь пройдя через многие объекты отношений, сознание становится само объектом самосознания» [1. С. 263]. Позже отечественный ученый Б.Д. Карвасарский утверждал, что именно отношение к себе, будучи наиболее поздним и зависимым от всех остальных, завершает становление структуры характера, системы отношений личности и обеспечивает ее целостность [6].

За рубежом проблемой Я-концепции занимались такие ученые, как У. Джеймс, Ч. Кулли, Дж. Мид, Э. Эриксон, К. Роджерс и др. В свое время Р. Бернс, идеи которого до сих пор встраиваются в научные исследования, на основании работ своих предшественников выделил разнообразные образы Я [4. С. 31-43; 10].

С его идеями невозможно не согласиться, так как Я-образ является неповторимой системой представлений человека о себе, на основании чего он выстраивает свое взаимодействие с другими. Имея двойственную природу, Я-образ выступает как установка по отношению к себе самому и как следствие социального взаимодействия. Никто не может действовать в противовес своим внутренним образам. Все наши действия, чувства, поступки согласуются с Я-образом. Он выступает в виде регулятора деятельности, вектором всего жизненного пути человека [3].

Формирование Я-образа, с одной стороны, происходит в результате рефлексии, самопознания, a c другой стороны, большое влияние на его развитие оказывают значимые другие люди, с которыми человек сталкивается в процессе своей жизнедеятельности [8. С. 124-135]. При каждом случае проявления человеком себя в обществе, при осуществлении восприятия сторонним наблюдателем, происходит взаимодействие Я-образа с образом другого человека, так называемым Ты-образом [10]. 
Функционирование людей друг с другом - встречный процесс, каждый из них выступает одновременно и объектом, и субъектом познания. Вследствие восприятия в процессе общения у людей возникает уникальная возможность наблюдать за внутренним миром другого, видеть характерологические свойства партнера по общению, в соответствии с которыми он будет выстраивать свое поведение по отношению к другому человеку [2].

По мнению С.И. Гусевой, родители имеют преимущество в оказании влияния на формирующийся Я-образ ребенка как личное представление ребенка о самом себе, поскольку именно они ориентируют детей в правильности и неправильности поступков, определяют характер взаимоотношений с людьми и влияют на социальное функционирование в течение всей жизни. Видимо, поэтому дети становятся такими, какими их воспринимают родители. Зачастую это может быть связано не столько с наложением собственного образа ребенка о самом себе и представлениями родителей о нем, сколько с формирующимся Мы-образом, складывающимся на основе детско-родительских отношений. Именно поэтому ребенок во многом будет ощущать себя так, как его видит значимое для него окружение близких взрослых [5].

Вместе с тем есть и другие мнения, в основе которых лежит убежденность в том, что ребенок социализируется не только в семье. Складывающаяся социальная ситуация развития на определенном этапе онтогенеза, разнообразные социальные общности, значимые для ребенка другие взрослые и сверстники могут оказывать существенное влияние на развитие его представлений о себе [7. С. 75, 93-110]. Например, отношение родителей к ребенку развивает систему его представлений о самом себе, влияет на уровень его притязаний, достижений, сказывается на установках и иных личностных характеристиках. Таким образом, наполненность детско-родительских взаимоотношений будет предопределять меру адекватности сформировавшегося образа Я.

По мнению В.Л. Ситникова, Я-образы матерей тесно связаны с Ты-образами их детей [10]. Правда, такая связь обнаруживается в отношении биологических родителей. В отношении приемных родителей подобных исследований нам не известно. В связи с этим мы предполагаем, что подобная связь может быть обнаружена и в отношении приемных родителей.

Приемная семья является одной из форм семейного устройства на воспитание детей-сирот и детей, оставшихся без попечения родителей, которая сравнительно недавно стала весьма интенсивно и фактически стихийно развиваться. Значимость развития семейных форм устройства при решении социальных вопросов была оценена в полной мере лишь за последние несколько десятков лет, также в связи с широким распространением зарубежного опыта $[15 ; 17 ; 18]$.

По нашему мнению, одной из них является проблема психологической безопасности семейной среды. Взаимоотношение с ребенком родителей, их личностные особенности могут способствовать тому, что ребенок начинает воспринимать себя беспомощным, слабым, неуверенным, относиться к себе как к жертве стечения обстоятельств. Это может способствовать тому, что его отношение с окружающими будет определяться негативным отношением к самому себе, которое может как минимум усложнять его жизнь, а как максимум - превратить в реальную жертву, сделать виктимным [12].

Известно, что приемные семьи проявляют заботу о детях, которые больше не могут жить со своими биологическими родителями. В опыте таких детей могут быть испытания пренебрежением, отказами, травматизацией и злоупотреблением. Из-за этих и других проблем, испытанных детьми до размещения в приемную семью, приемные родители могут быть подвержены вынужденному риску встречи с детьми, которые имеют психологические расстройства, задержки развития, хронические проблемы со здоровьем и проблемное поведение. Соответственно, стабильность семейной системы и непрерывность ее развития должны обеспечивать создание ресурсных отношений, которые повысят вероятность снижения негативных проблем у приемных детей [16].

В связи с этим приемным родителям необходимы личностные ресурсы, позволяющие справляться с трудностями, закономерно возникающими при взаимодействии с приемными детьми. По нашему мнению, одним из таких ресурсов может стать Я-концепция, а именно адекватный Я-образ. Положение о том, что самосознание влияет на поведение человека и на его отношения с окружающей действительностью является вполне оправданным, так как чем выше уровень качеств самосознания, тем выше ценность субъекта в представлении о самом себе. В свою очередь, осознание собственной ценности может оказать значительное влияние на других людей, в том числе и на детей, принятых на воспитание в семью, благодаря чему будет развиваться ориентировочная основа в проявлении своего отношения к другим людям и к самому себе. 


\section{Гипотеза исследования}

Между структурными компонентами образов приемных матерей и образов приемных детей есть структурно-статистическая и качественно-содержательная связь.

\section{Цель исследования}

Целью нашего исследования стало определение особенностей структурных и содержательных характеристик Я-образов приемных матерей и Ты-образов их приемных детей, а также определение достоверных различий и взаимосвязей в этих социально-перцептивных образах.

\section{Задачи исследования}

1. Выявить достоверные различия в структурных характеристиках социально-перцептивных образов.

2. Раскрыть взаимосвязи структурных компонентов Я-, Ты-образов.

3. Определить содержательные характеристики социально-перцептивных образов.

\section{материал и методы}

Материалом послужили труды зарубежных, российских и белорусских ученых, затрагивающие проблему социально-перцептивных образов. Для реализации цели применялись теоретические и эмпирические методы. В исследовании использовалась методика «СОЧ(И)» - структура образа человека (иерархическая) (В.Л. Ситников) [9]. Работа была проведена с участием 78 человек, приемных матерей в возрасте от 29 до 66 лет $(\mathrm{M}=49,64 ; \mathrm{SD}=7,54)$.

Методы математической статистики: метод ранжирования, описательная статистика, Т-критерий Вилкоксона, критерий Тау-b Кендалла, непараметрический критерий хи ${ }^{2}$-статистики, критерий гамма-статистики. Статистическая обработка осуществлялась с помощью программы IBM SPSS Statistics 23 for Windows.

\section{Результаты исследования}

В результате проведенного частотного анализа методики «СОЧ(И)» нами были получены результаты по показателям среднего значения, ранжирования, минимального и максимального количества названных характеристик. Также были получены результаты, по которым можно судить о количестве респондентов, которые не использовали возможные характеристики при описании самого себя и ребенка (табл. 1).

Таблица 1

Результаты ранжирования структурных компонентов социально-перцептивных образов

\begin{tabular}{|l|c|c|c|c|c|c|c|c|c|c|}
\hline $\begin{array}{l}\text { Я-образ приемных } \\
\text { матерей (n=78) }\end{array}$ & В & Д & И & ИС & К & П & С & Т & Э & М \\
\hline среднее значение & 2,64 & 1,99 & 2,06 & 1,88 & 1,55 & 0,60 & 8,88 & 1,83 & 6,18 & 0,60 \\
\hline Ранг & 3 & 5 & 4 & 6 & 8 & 9 & 1 & 7 & 2 & 9 \\
\hline наименьшее кол-во & 0 & 0 & 0 & 0 & 0 & 0 & 1 & 0 & 0 & 0 \\
\hline наибольшее кол-во & 7 & 8 & 7 & 6 & 10 & 3 & 18 & 5 & 12 & 7 \\
\hline не назвали & 4 & 14 & 16 & 12 & 39 & 48 & 0 & 13 & 1 & 61 \\
\hline $\begin{array}{l}\text { Ты-образ приемных } \\
\text { матерей (п=78) }\end{array}$ & $\mathrm{B}$ & Д & И & ИС & К & П & С & Т & $Э$ & М \\
\hline среднее значение & 2,69 & 1,63 & 2,44 & 1,26 & 0,35 & 1,05 & 8,63 & 2,71 & 6,58 & 0,40 \\
\hline Ранг & 4 & 6 & 5 & 7 & 10 & 8 & 1 & 3 & 2 & 9 \\
\hline наименьшее кол-во & 0 & 0 & 0 & 0 & 0 & 0 & 2 & 0 & 1 & 0 \\
\hline наибольшее кол-во & 6 & 6 & 7 & 4 & 2 & 4 & 15 & 9 & 12 & 9 \\
\hline не назвали & 8 & 17 & 6 & 20 & 56 & 26 & 0 & 8 & 0 & 65 \\
\hline
\end{tabular}

Как видно из табл. 1, на первых двух ранговых местах располагаются социальные и эмоциональные характеристики. Начиная с третьего места видны отличительные особенности. Так, на третьем ранговом месте в образах мам наблюдаются волевые, а на том же самом месте в образах ребенка телесные характеристики. Вместе с тем по распределению средних значений можно сделать предположение, что некоторые из них обладают сходством, а отдельные структурные характеристики имеют существенные различия. Чаще всего в образах матерей при описании самих себя указываются соци- 
альные характеристики (в среднем 8,88) - это ранг 1, далее эмоциональные (в среднем 6,18) - это ранг 2, затем волевые (в среднем 2,64) - это ранг 3 . На последних трех местах в порядке убывания отмечаются - конвенциональные, поведенческие и метафорические характеристики.

Наряду с тем, в Я-образах приемных матерей количество социальных характеристик варьируется от $\min (1)$ до $\max (18)$; количество эмоциональных определяется от $\min (0)$ до $\max (12)$ определений; количество волевых характеристик варьируется от $\min (0)$ до $\max (7)$. Соответственно, при описании Я-образов приемные матери чаще приводят социальные, эмоциональные, метафорические характеристики и реже - конвенциональные, поведенческие и характеристики социального интеллекта.

При аналогичном сравнении чаще всего в образах детей указываются социальные характеристики (в среднем 8,63) - это ранг 1, далее эмоциональные (в среднем 6,58) - это ранг 2, затем телесные (в среднем 2,71) - это ранг 3. На последних трех местах в порядке убывания отмечаются поведенческие, метафорические и конвенциональные характеристики.

При этом в Ты-образах приемных детей количество социальных характеристик варьируется от $\min (2)$ до $\max (15)$; количество эмоциональных определяется от $\min (1)$ до $\max (12)$ определений; количество телесных характеристик варьируется от $\min (0)$ до $\max (9)$. Так, аналогичным образом, как и при описании себя, приемные матери при воссоздании Ты-образов чаще приводят социальные, эмоциональные, метафорические характеристики и реже - конвенциональные, поведенческие и характеристики социального интеллекта.

В равной мере были проанализировали данные средних значений по характеристикам разной модальности. Как видно из рис. 1, положительные и нейтральные характеристики в двух образах имеют похожее распределение по сравнению с показателями отрицательных компонентов. Большая их часть имеется в образах приемного ребенка. А вот в Я-образах таких компонентов вдвое меньше по сравнению с детскими образами. В связи с этим не вызывает сомнения то, что приемный ребенок матерями будет восприниматься эмоционально, причем валентность проявления чувств склоняется в сторону неприятных переживаний.

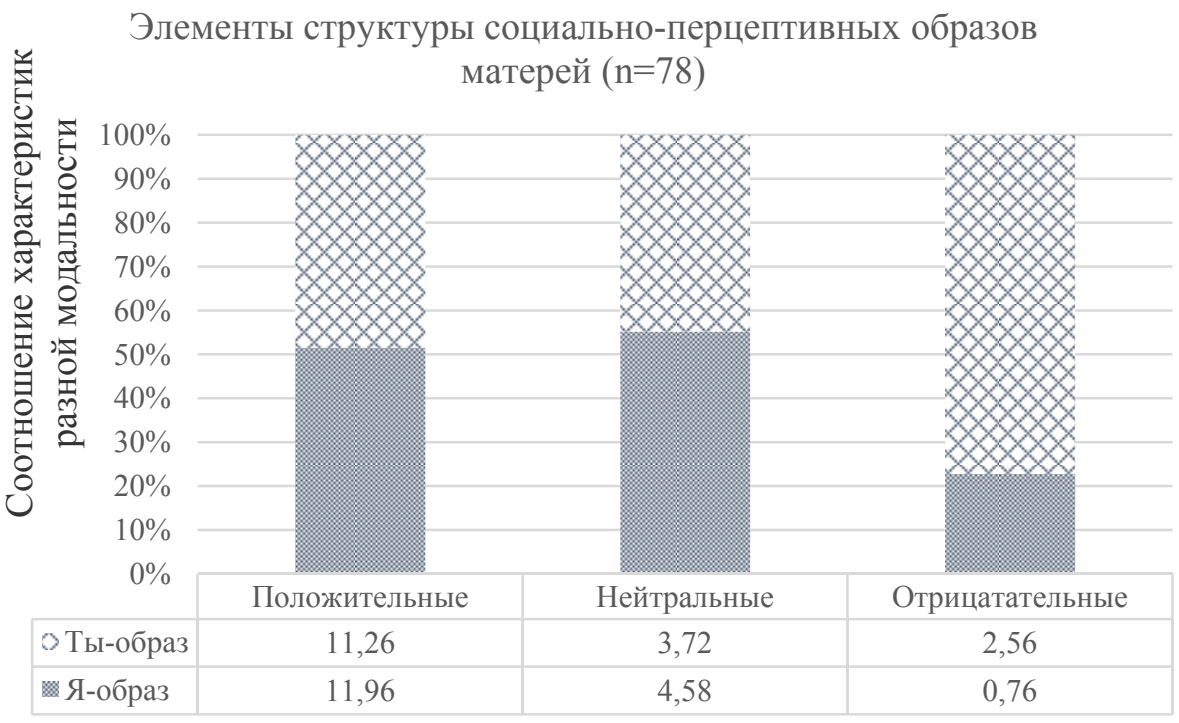

Рис. 1. Сравнение характеристик образов по модальности

По нашему мнению, такая особенность может быть связана с психологической готовностью у приемных матерей воспринимать и думать о приемном ребенке хуже, чем он есть на самом деле. Видимо, выявленная особенность будет характерна для приемных родителей, о ней в свое время говорила А.С. Спиваковская как о негативном явлении, в основе которого лежит родительская тревога за неблагополучный генофонд приемного ребенка $[11 ; 14]$. Подобная установка на восприятие приемного ребенка у родителей может развивать неуверенность в своей профессиональной компетентности и воспитательных потенциалах.

В результате, несмотря на внешнее подобие структур содержательных компонентов двух образов, изучаемые образы имеют различия по параметрам валентности. 
В дальнейшем полученные данные были подвергнуты статистическому анализу. С помощью критерия Колмогорова-Смирнова были получены результаты об отсутствии нормального распределения изучаемых переменных.

Нами была проведена описательная статистика. Выявленные показатели по социально-перцептивным образам не имеют нормального распределения и имеют большое количество выбросов (рис. 2).
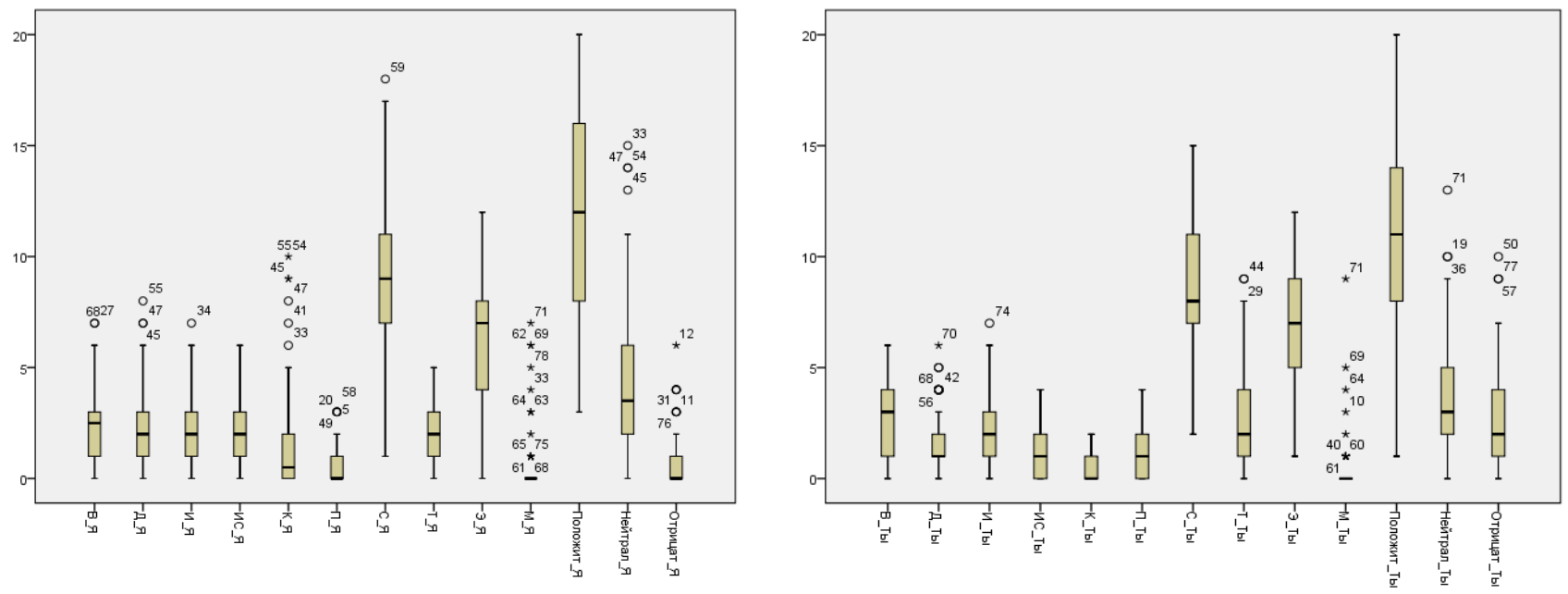

Рис. 2. Диаграмма размаха показателей структур материнских и детских образов

Полученные предварительные результаты обусловили выбор критерия для последующего анализа данных. Для проверки гипотезы о статистическом различии в показателях структуры Я-, Тыобразов матерей нами был использован Т-критерий Вилкоксона.

На основании проведенного анализа были обнаружены следующие различия по структурным компонентам образов (табл. 2).

Таблица 2

Результаты проверки гипотезы о достоверности различий в социально-перцептивных образах приемных матерей

\begin{tabular}{|c|c|c|c|c|c|c|c|c|c|c|c|c|c|}
\hline \multicolumn{14}{|c|}{ Статистические критерии $^{\mathrm{a}}$} \\
\hline & $\begin{aligned} \mathrm{B} 2- \\
\mathrm{B} 1\end{aligned}$ & $\begin{array}{l}\text { Д2- } \\
\text { Д1 }\end{array}$ & $\begin{array}{r}\text { И } 2- \\
\text { И1 }\end{array}$ & $\begin{aligned} \text { ИС2 } 2- \\
\text { ИС } 1\end{aligned}$ & $\begin{array}{r}\mathrm{K} 2- \\
\mathrm{K} 1\end{array}$ & $\begin{array}{r}\Pi 2- \\
\Pi 1\end{array}$ & $\begin{array}{r}\mathrm{C} 2- \\
\mathrm{C} 1\end{array}$ & $\begin{array}{c}\mathrm{T} 2- \\
\mathrm{T} 1\end{array}$ & $\begin{aligned} \ni 2- \\
Э 1\end{aligned}$ & $\begin{aligned} \mathrm{M} 2- \\
\mathrm{M} 1\end{aligned}$ & $\begin{aligned}+" 2- \\
"+" 1\end{aligned}$ & $\begin{array}{l}==" 2- \\
"=" 1\end{array}$ & $\begin{array}{l}-2- \\
\text { "-"1 }\end{array}$ \\
\hline $\mathrm{Z}$ &,$- 009 \mathrm{~b}$ & $-1,384 c$ & $-1,649 b$ & $-3,098 \mathrm{c}$ & $-1,319 c$ & $-2,856 \mathrm{~b}$ &,$- 198 \mathrm{~b}$ & $-2,558 \mathrm{~b}$ &,$- 783 b$ &,$- 957 \mathrm{~b}$ & $-1,182 c$ & $-2,105 b$ & $-3,488 \mathrm{~b}$ \\
\hline $\begin{array}{l}\text { Асимптотическая } \\
\text { значимость } \\
\text { (двухсторонняя) }\end{array}$ & ,993 & ,166 & ,099 & ,002 & 187 & ,004 & 843 & ,011 & ,434 & ,339 & 237 & ,035 & ,000 \\
\hline \multicolumn{14}{|c|}{ а. Критерий знаковых рангов Вилкоксона } \\
\hline \multirow{2}{*}{\multicolumn{14}{|c|}{ b. На основе отрицательных рангов }} \\
\hline с. На основе поло & китель & ных pal & нгов & & & & & & & & & & \\
\hline
\end{tabular}

Условные обозначения: В1 - волевые характеристики образов матерей, В2 - волевые характеристики образов детей, Д1 - деятельностные характеристики образов матерей, Д2 - деятельностные характеристики образов детей, И1 - интеллектуальные характеристики образов матерей, И2 - интеллектуальные характеристики образов детей, ИС1 - интеллект социальный образов матерей, ИС2 - интеллект социальный образов детей, К1 - конвенциональные характеристики образов матерей, К2 - конвенциональные характеристики образов детей, П1 - поведенческие характеристики образов матерей, П2 - поведенческие характеристики образов детей, $\mathrm{C} 1$ - социальные характеристики образов матерей, $\mathrm{C} 2$ - социальные характеристики образов детей, Т1 - телесные характеристики образов матерей, Т2 - телесные характеристики образов детей, Э1 - эмоциональные характеристики образов матерей, Э2 - эмоциональные характеристики образов детей, М1 - метафорические характеристики образов матерей, М2 - метафорические характеристики образов детей, «+»1 - положительные характеристики образов матерей, «+»2 - положительные 
характеристики образов детей, «=» 1 - нейтральные характеристики образов матерей, «=» 2 - нейтральные характеристики образов детей, «-»1 - отрицательные характеристики образов матерей, «-»2 - отрицательные характеристики образов детей.

На основании проведенного анализа были выявлены достоверные различия по пяти структурным характеристикам образов, таким как интеллект социальный $(\mathrm{p} \leq 0,05)$, поведенческие $(\mathrm{p} \leq 0,05)$, телесные $(\mathrm{p} \leq 0,05)$, нейтральные $(\mathrm{p} \leq 0,05)$, отрицательные $(\mathrm{p} \leq 0,05)$.

Вместе с тем различия отсутствуют по 8-и структурным характеристикам: волевым (p>0,05), деятельностным ( $>0,05)$, интеллектуальным ( $>>0,05)$, конвенциональным ( $>0,05)$, социальным $(\mathrm{p}>0,05)$, эмоциональным ( $>0,05)$, метафорическим ( $>>0,05)$, положительным $(\mathrm{p}>0,05)$.

В дальнейшем была сформулирована гипотеза о наличии взаимоотношений структурных компонентов изучаемых образов. По нашему мнению, можно предположить, что между структурными компонентами образов приемных матерей и образов приемных детей есть структурно-статистическая связь. Корреляционный анализ проводился с помощью непараметрического критерия Тay-b Кендалла.

В сопоставлении Я-образов приемных матерей и Ты-образов приемных детей было выявлено 27 корреляций, из которых 25 - положительные и 2 - отрицательные (табл. 3).

Таблица 3

Показатели корреляций при парном сравнении социально-перцептивных образов

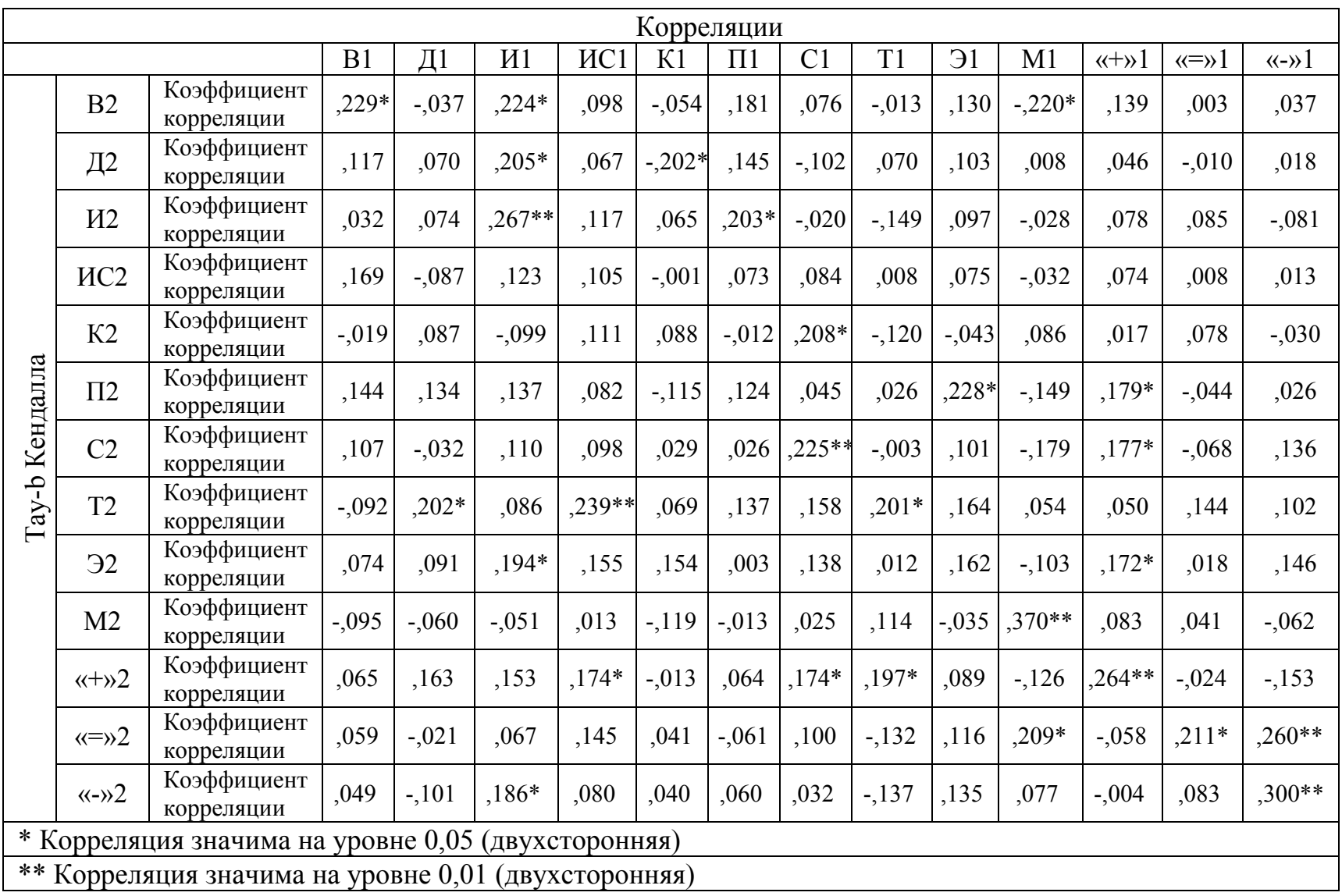

Условные обозначения: аналогично табл. 2.

На основании полученных данных по корреляционному анализу можно сказать о том, что сравниваемые переменные структурных компонентов образов имеют внушительное количество совпадений. На этом основании мы делаем предположение о том, что структурные характеристики изучаемых двух образов соотносятся между собой. Более того, мы считаем, что образ приемного ребенка в сознании приемной матери выстраивается по механизму проекции.

В дальнейшем проводилась проверка по определению связей между различными переменными образов. С помощью критерия хиํ-статистики было сделано 27 проверок. Так, при проверке гипотезы 
о зависимости переменных она подтверждается по 20 корреляциям структурных компонентов изучаемых образов. Это по таким, как: деятельностные характеристики Я-образов и телесные характери-

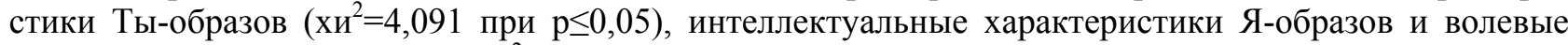
характеристики Ты-образов (хи ${ }^{2}=5,400$ при $\left.\mathrm{p} \leq 0,05\right)$, интеллектуальные характеристики Я-образов и интеллектуальные характеристики Ты-образов $\left(\right.$ хи $^{2}=8,067$ при $\left.\mathbf{p} \leq 0,05\right)$, интеллектуальные характеристики Я-образов и эмоциональные характеристики Ты-образов $\left(\right.$ хи $^{2}=68,211$ при р $\left.\leq 0,05\right)$, интеллект социальный Я-образов и телесные характеристики Ты-образов $\left(\right.$ хи $^{2}=13,755$ при $\left.\mathrm{p} \leq 0,05\right)$, интеллект социальный Я-образов и положительные характеристики Ты-образов (хи $2=78,000$ при p $\leq 0,05)$, конвенциональные характеристики Я-образов и деятельностные характеристики Ты-образов (хи ${ }^{2}=4,188$ при $\mathrm{p} \leq 0,05)$, поведенческие характеристики Я-образов и интеллектуальные характеристики Тыобразов $\left(\right.$ хи $^{2}=50,970$ при $\left.\mathrm{p} \leq 0,05\right)$, социальные характеристики Я-образов и конвенциональные характеристики Ты-образов (хи ${ }^{2}=77,000$ при $\left.\mathrm{p} \leq 0,05\right)$, социальные характеристики Я-образов и положительные характеристики Ты-образов (хи ${ }^{2}=14,222$ при $\left.\mathrm{p} \leq 0,05\right)$, телесные характеристики Я-образов и телесные характеристики Ты-образов (хи ${ }^{2}=9,281$ при $\left.\mathrm{p} \leq 0,05\right)$, телесные характеристики Я-образов и положительные характеристики Ты-образов (хи ${ }^{2}=78,000$ при $\left.\mathbf{p} \leq 0,05\right)$, эмоциональные характеристики Яобразов и поведенческие характеристики Ты-образов (хи ${ }^{2}=72,053$ при $\left.\mathrm{p} \leq 0,05\right)$, метафорические характеристики Я-образов и волевые характеристики Ты-образов (хи ${ }^{2}=41,657$ при $\left.\mathrm{p} \leq 0,05\right)$, метафорические характеристики Я-образов и нейтральные характеристики Ты-образов (хи ${ }^{2}=67,213$ при $\left.\mathbf{p} \leq 0,05\right)$, положительные характеристики Я-образов и поведенческие характеристики Ты-образов $\left(\mathrm{xи}^{2}=78,000\right.$ при $\mathrm{p} \leq 0,05)$, положительные характеристики Я-образов и социальные характеристики Ты-образов $\left(\right.$ хи $^{2}=18,000$ при $\left.\mathrm{p} \leq 0,05\right)$, положительные характеристики Я-образов и эмоциональные характеристики Ты-образов (хи ${ }^{2}=50,970$ при $\left.\mathrm{p} \leq 0,05\right)$, отрицательные характеристики Я-образов и нейтральные характеристики Ты-образов (хи른 $=65,219$ при $\mathrm{p} \leq 0,05)$, отрицательные характеристики Я-образов и отрицательные характеристики Ты-образов (хи ${ }^{2}=34,322$ при $\left.\mathbf{p} \leq 0,05\right)$.

Впоследствии с целью установления силы взаимосвязей между структурными компонентами образов полученные итоги корреляционного анализа были подвергнуты проверке по критерию гамма-статистики (табл. 4).

Таблица 4

\section{Показатели силы взаимосвязи между переменными социально-перцептивных образов}

\begin{tabular}{|l|l|c|c|c|}
\hline \multicolumn{1}{|c|}{ Структура Я-образов } & \multicolumn{1}{|c|}{$\begin{array}{c}\text { Структура } \\
\text { Ты-образов }\end{array}$} & $\begin{array}{c}\text { Значение } \\
\text { гамма }\end{array}$ & $\begin{array}{c}\text { Приблизительная } \\
\text { значимость }\end{array}$ & $\begin{array}{c}\text { Сила взаимосвязи } \\
\text { (шкала Чедокка) }\end{array}$ \\
\hline Деятельностные & Телесные & 0,241 & 0,036 & Слабая \\
\hline Интеллектуальные & Волевые & 0,267 & 0,01 & Слабая \\
\hline Интеллектуальные & Эмоциональные & 0,226 & 0,021 & Слабая \\
\hline Интеллект социальный & Телесные & 0,288 & 0,011 & Слабая \\
\hline Интеллект социальный & Положительные & 0,202 & 0,042 & Слабая \\
\hline Конвенциональные & Деятельностные & $-0,273$ & 0,015 & Слабая \\
\hline Поведенческие & Интеллектуальные & 0,299 & 0,022 & Слабая \\
\hline Социальные & Положительные & 0,188 & 0,025 & Слабая \\
\hline Телесные & Телесные & 0,243 & 0,02 & Слабая \\
\hline Телесные & Положительные & 0,228 & 0,018 & Слабая \\
\hline Эмоциональные & Поведенческие & 0,285 & 0,006 & Слабая \\
\hline Положительные & Поведенческие & 0,221 & 0,02 & Слабая \\
\hline Положительные & Социальные & 0,193 & 0,041 & Слабая \\
\hline Положительные & Эмоциональные & 0,187 & 0,035 & Слабая \\
\hline Интеллектуальные & Интеллектуальные & 0,326 & 0,002 & Умеренная \\
\hline Социальные & Конвенциональные & 0,331 & 0,013 & Умеренная \\
\hline Метафорические & Волевые & $-0,393$ & 0,015 & Умеренная \\
\hline Метафорические & Нейтральные & 0,358 & 0,031 & Умеренная \\
\hline Отрицательные & Нейтральные & 0,363 & 0,002 & Умеренная \\
\hline Отрицательные & Отрицательные & 0,419 & 0,001 & Умеренная \\
\hline
\end{tabular}


Нами были получены показатели по силе взаимосвязи структурных компонентов изучаемых образов. Из них оказались слабыми 14 корреляций, умеренными - 6 корреляций. Как видно из таблицы 4, в сравнениях чаще встречаются интеллектуальные, положительные, телесные и социальные характеристики, реже - конвенциональные характеристики и характеристики социального интеллекта.

По нашему мнению, нет смысла в описании всех полученных корреляций. Обращает на себя внимание их количество, а также теснота связей структур изучаемых образов. Важно отметить, что, несмотря на приличную численность взаимосвязей, по силе они являются недостаточно прочными. Вместе с тем достаточно часто встречаются связи, которые включают характеристики, отражающие отношение к человеку. К ним В.Л. Ситников относит метафорические, положительные, нейтральные и отрицательные характеристики [9. С. 132].

Также нами были проанализированы содержательные характеристики социально-перцептивных образов группы приемных матерей. На основании данных частотных словарей по двум образам можно выделить одинаковые характеристики (табл. 5).

Таблица 5

Сравнительная характеристика содержания социально-перцептивных образов приемных матерей

\begin{tabular}{|c|c|c|c|c|c|c|}
\hline № & Я-образ & $\begin{array}{c}\text { Абс. } \\
\text { частот. }\end{array}$ & $\begin{array}{c}\text { Отн. } \\
\text { частот. }\end{array}$ & Ты-образ & $\begin{array}{c}\text { Абс. } \\
\text { частот. }\end{array}$ & $\begin{array}{c}\text { Отн. } \\
\text { частот. }\end{array}$ \\
\hline 1 & добрая & 36 & $46 \%$ & добрый & 43 & $55 \%$ \\
\hline 2 & трудолюбивая & 26 & $33 \%$ & ласковый & 37 & $47 \%$ \\
\hline 3 & веселая & 23 & $29 \%$ & любимый & 22 & $28 \%$ \\
\hline 4 & заботливая & 22 & $28 \%$ & веселый & 21 & $27 \%$ \\
\hline 5 & ответственная & 22 & $28 \%$ & умный & 21 & $27 \%$ \\
\hline 6 & справедливая & 17 & $22 \%$ & трудолюбивый & 20 & $26 \%$ \\
\hline 7 & отзывчивая & 15 & $19 \%$ & красивый & 18 & $23 \%$ \\
\hline 8 & дружелюбная & 14 & $18 \%$ & любознательный & 15 & $19 \%$ \\
\hline 9 & аккуратная & 13 & $17 \%$ & ответственный & 14 & $18 \%$ \\
\hline 10 & внимательная & 13 & $17 \%$ & отзывчивый & 14 & $18 \%$ \\
\hline 11 & мама & 13 & $17 \%$ & аккуратный & 12 & $15 \%$ \\
\hline 12 & любящая & 12 & $15 \%$ & дружелюбный & 12 & $15 \%$ \\
\hline 13 & нежная & 12 & $15 \%$ & заботливый & 12 & $15 \%$ \\
\hline 14 & женщина & 11 & $14 \%$ & общительный & 11 & $14 \%$ \\
\hline 15 & ласковая & 11 & $14 \%$ & помощник & 11 & $14 \%$ \\
\hline 16 & любимая & 11 & $14 \%$ & быстрый & 10 & $13 \%$ \\
\hline 17 & любознательная & 11 & $14 \%$ & послушный & 10 & $13 \%$ \\
\hline 18 & строгая & 10 & $13 \%$ & хороший & 10 & $13 \%$ \\
\hline 19 & терпеливая & 10 & $13 \%$ & интересный & 9 & $12 \%$ \\
\hline 20 & хозяйственная & 10 & $13 \%$ & скромный & 9 & $12 \%$ \\
\hline 21 & интересная & 9 & $12 \%$ & спортивный & 9 & $12 \%$ \\
\hline 22 & красивая & 9 & $12 \%$ & активный & 8 & $10 \%$ \\
\hline 23 & понимающая & 9 & $12 \%$ & обидчивый & 8 & $10 \%$ \\
\hline 24 & симпатичная & 9 & $12 \%$ & самостоятельный & 8 & $10 \%$ \\
\hline 25 & умная & 9 & $12 \%$ & вежливый & 7 & $9 \%$ \\
\hline 26 & жизнерадостная & 7 & $9 \%$ & внимательный & 7 & $9 \%$ \\
\hline 27 & люблю детей & 7 & $9 \%$ & воспитанный & 7 & $9 \%$ \\
\hline 28 & целеустремленная & 7 & $9 \%$ & заботливый & 7 & $9 \%$ \\
\hline 29 & человек & 7 & $9 \%$ & капризный & 7 & $9 \%$ \\
\hline 30 & честная & 7 & $9 \%$ & нежный & 7 & $9 \%$ \\
\hline 31 & гостеприимная & 6 & $8 \%$ & радостный & 7 & $9 \%$ \\
\hline 32 & друг & 6 & $8 \%$ & честный & 7 & $9 \%$ \\
\hline 33 & коммуникабельная & 6 & $8 \%$ & артистичный & 6 & $8 \%$ \\
\hline 34 & надежная & 6 & $8 \%$ & жалостливый & 6 & $8 \%$ \\
\hline 35 & скромная & 6 & $8 \%$ & застенчивый & 6 & $8 \%$ \\
\hline
\end{tabular}


А.А. Стреленко

\begin{tabular}{|c|c|c|c|c|c|c|}
\hline & & & & & & \\
\hline 36 & активная & 5 & $6 \%$ & люОоПЫтныИ & 6 & $8 \%$ \\
\hline 37 & доброжелательная & 5 & $6 \%$ & гиперактивный & 5 & $6 \%$ \\
\hline 38 & дочь & 5 & $6 \%$ & жизнерадостный & 5 & $6 \%$ \\
\hline 39 & жалостливая & 5 & $6 \%$ & игривый & 5 & $6 \%$ \\
\hline 40 & люблю готовить & 5 & $6 \%$ & исполнительный & 5 & $6 \%$ \\
\hline 41 & обидчивая & 5 & $6 \%$ & коммуникабельный & 5 & $6 \%$ \\
\hline 42 & общительная & 5 & $6 \%$ & разговорчивый & 5 & $6 \%$ \\
\hline 43 & повар & 5 & $6 \%$ & симпатичный & 5 & $6 \%$ \\
\hline 44 & ранимая & 5 & $6 \%$ & сострадание & 5 & $6 \%$ \\
\hline 45 & спокойная & 5 & $6 \%$ & старательный & 5 & $6 \%$ \\
\hline 46 & спортивная & 5 & $6 \%$ & хитрый & 5 & $6 \%$ \\
\hline 47 & требовательная & 5 & $6 \%$ & бережливый & 4 & $5 \%$ \\
\hline 48 & хозяйка & 5 & $6 \%$ & девочка & 4 & $5 \%$ \\
\hline 49 & чистоплотная & 5 & $6 \%$ & доверчивый & 4 & $5 \%$ \\
\hline 50 & бабушка & 4 & $5 \%$ & контактный & 4 & $5 \%$ \\
\hline 51 & воспитатель & 4 & $5 \%$ & ленивый & 4 & $5 \%$ \\
\hline 52 & жена & 4 & $5 \%$ & любит животных & 4 & $5 \%$ \\
\hline 53 & задумчивая & 4 & $5 \%$ & маленький человек & 4 & $5 \%$ \\
\hline 54 & застенчивая & 4 & $5 \%$ & медлительный & 4 & $5 \%$ \\
\hline 55 & искренняя & 4 & $5 \%$ & мечтательный & 4 & $5 \%$ \\
\hline 56 & кошечка & 4 & $5 \%$ & милый & 4 & $5 \%$ \\
\hline 57 & люблю животных & 4 & $5 \%$ & надежный & 4 & $5 \%$ \\
\hline 58 & любящая мама & 4 & $5 \%$ & не жадный & 4 & $5 \%$ \\
\hline 59 & мечтательная & 4 & $5 \%$ & открытый & 4 & $5 \%$ \\
\hline 60 & музыкальная & 4 & $5 \%$ & понимающий & 4 & $5 \%$ \\
\hline 61 & организатор & 4 & $5 \%$ & смешной & 4 & $5 \%$ \\
\hline 62 & открытая & 4 & $5 \%$ & солнышко & 4 & $5 \%$ \\
\hline 63 & подруга & 4 & $5 \%$ & спокойный & 4 & $5 \%$ \\
\hline 64 & постоянная & 4 & $5 \%$ & счастливый & 4 & $5 \%$ \\
\hline 65 & с чувством юмора & 4 & $5 \%$ & танцевальная & 4 & $5 \%$ \\
\hline 66 & серьезная & 4 & $5 \%$ & терпеливый & 4 & $5 \%$ \\
\hline 67 & сестра & 4 & $5 \%$ & требующий внимания & 4 & $5 \%$ \\
\hline 68 & сильная & 4 & $5 \%$ & хозяйственная & 4 & $5 \%$ \\
\hline 69 & счастливая & 4 & $5 \%$ & целеустремленный & 4 & $5 \%$ \\
\hline 70 & уверенная & 4 & $5 \%$ & шумный & 4 & $5 \%$ \\
\hline 71 & уступчивая & 4 & $5 \%$ & шустрый & 4 & $5 \%$ \\
\hline 72 & учитель & 4 & $5 \%$ & болезнь & 3 & $4 \%$ \\
\hline 73 & хорошая & 4 & $5 \%$ & друг & 3 & $4 \%$ \\
\hline 74 & хорошая мама & 4 & $5 \%$ & задумчивый & 3 & $4 \%$ \\
\hline 75 & чувствительная & 4 & $5 \%$ & искренний & 3 & $4 \%$ \\
\hline 76 & щедрая & 4 & $5 \%$ & котик & 3 & $4 \%$ \\
\hline 77 & эмоциональная & 4 & $5 \%$ & лидер & 3 & $4 \%$ \\
\hline 78 & доверчивая & 3 & $4 \%$ & любит читать & 3 & $4 \%$ \\
\hline
\end{tabular}

Условные обозначения: жирным шрифтом выделены повторяющиеся характеристики.

Как видно из табл. 5, качественный анализ, проведенный на основе обобщения частоты встречаемых характеристик при описании образов, свидетельствует о том, что между ними есть выраженная конвергенция.

При сравнении дословных совпадений двух образов в представлениях приемных матерей можно выделить обобщенные характеристики, которые встречаются в двух образах. Так, приемные матери воспринимают себя и своих приемных детей: добрыми, трудолюбивыми, весельми, заботливыми, ответственными, отзывчивыми, дружелюбными, аккуратными, внимательными, нежными, ласковыми, любимыми, любознательными, терпеливыми, интересными, красивыми, симпатичными, ум- 
ными, жизнерадостными, иелеустремленными, честными, коммуникабельными, скромными, активными, жалостливыми, обидчивыми, общительными, спокойныли, спортивными, задумчивыми, застенчивыли, мечтательными, открытыми, счастливыми, хорошими, хозяйственныли, искренними, доверчивыми, понимающими, любямими животных, друзьями.

Помимо обобщенных характеристик, в описываемых образах встречаются и непохожие характеристики, но их наличие детализирует воспринимаемый образ. Так, в образах приемных матерей встречаются описания о самих себе: справедливая, мама, любящая, женщина, строгая, любящая детей, человек, гостеприимная, надежная, доброжелательная, дочь, любящая готовить, повар, ранимая, требовательная, хозяйка, чистоплотная, бабушка, воспитатель, жена, любящая мама, музыкальная, организатор, подруга, постоянная, с чувством юмора, серьезная, сестра, сильная, уверенная, уступчивая, учитель, хорошая мама, чувствительная, щедрая, эмочиональная.

Аналогично предыдущему сравнению в детских образах также определяются не похожие на предыдущий образ характеристики: Например, заботливый, помощник, быстрый, послушный, самостоятельныгй, вежсливый, воспитанный, капризный, радостный, артистичныій, любопылтный, гиперактивный, игривый, исполнительныгй, сострадающий, старательный, хитрый, бережливый, контактный, ленивый, маленький человек, девочка, медлительный, мильй, надежный, не жадный, смешной, солнышко, танцевальный, требующий внимания, шумный, шустрый, болезненный, лидер, любящий читать.

\section{Обсуждение результатов}

Сравнение социально-перцептивных образов приемных матерей по структуре и по содержанию указывает на близость образов матерей и образов их приемных детей. Возможно, что таким способом определяется единый механизм формирования изучаемых нами социально-перцептивных образов. На основании подобного механизма приемные матери, как правило, выбирают ребенка и выстраивают в дальнейшем взаимодействие с ним, опираясь не столько на отражение реальных личностных особенностей самого ребенка, сколько на собственные представления о самой себе, на свою Я-концепцию.

По результатам проведенного исследования определяется, что образ себя у приемных матерей имеет более выраженную положительную или нейтральную модальность, а вот образ приемного ребенка имеет более выраженную отрицательную модальность. Вероятно, приемные мамы оценивают себя более адекватно и самокритично по сравнению с представлениями о своих приемных детях. Возможно, что формирующийся образ приемного ребенка в сознании приемных матерей будет оформляться как менее адекватный в силу недостаточной информации о самом ребенке, его личностных особенностях на различных возрастных этапах развития, как правило предшествующих попаданию в приемную семью.

Помимо определяемого на первый взгляд внешнего сходства структурных характеристик социально-перцептивных образов приемных матерей, нами были определены достоверные различия, которые можно рассматривать как определяющие характеристики в выделении себя и другого в ходе социального восприятия.

Так, достоверные различия по показателям социального интеллекта нами рассматриваются как то, что в отличие от взрослого человека ребенок по своим возрастным особенностям еще не в полную свою силу может быть способным распознавать и понимать поведение других людей. Функция прогноза и предвидения еще недоступна маленькому ребенку, чего нельзя сказать о взрослом человеке, который уже в силу возрастных особенностей и своего жизненного опыта может предвосхищать поведение других людей, а следовательно, и прогнозировать различные ситуации. Достоверные различия по поведенческим характеристикам социально-перцептивных образов рассматриваются как особенности поступков человека. Возможно, что приемные матери считают себя более ответственными в своих поступках по отношению к другим людям, а приемных детей рассматривают пока как менее ответственных, менее исполнительных, но более доверчивых и общительных людей. Также достоверные различия отмечаются по телесным характеристикам, что вполне естественно при сравнении внешнего облика взрослого человека и облика ребенка. Различия по нейтральным и отрицательным характеристикам нами связываются с отраженным отношением к себе и другому. По-видимому, при взаимодействии с приемным ребенком у приемных матерей будут преобладать такие эмоции и субъективные переживания, которые отличаются от эмоций и переживаний по отношению к самому себе. Вероятно, чувства, испытываемые к ребенку и самому себе, будут различаться по модальности, по интенсивности, по содержанию и по характеру стеничности. 


\section{Заключение и выводы}

Исследование различий и связей социально-перцептивных Я-образов приемных матерей с Тыобразами своих приемных детей позволяет судить о том, что структурно-содержательный анализ вербальных характеристик дает возможность выявлять особенности структуры и содержания социально-перцептивных образов:

1) Я- и Ты-образы приемных матерей имеют похожие структуры;

2) Я-образы приемных матерей по своей структуре тесно связаны с образами приемных детей;

3) содержательная связь, выявленная между элементами Я-образов приемных матерей, и Тыобразами их приемных детей, также подтверждает гипотезу о тесноте их связи;

4) достоверные различия определяются по когнитивному, регулятивному и конативному компонентам самосознания приемных матерей, а также по валентным характеристикам их социальноперцептивных образов.

Таким образом, результаты эмпирического исследования показали, что Я-образы приемных матерей и образы приемных детей соотносятся между собой по структуре и по содержанию. Повидимому, в основе их развития лежит единый механизм проекции, который и будет способствовать осуществлению выбора приемного ребенка. Причем такой выбор у приемных мам реализуется не столько на основе отражения реалистичных особенностей приемных детей, сколько с ориентацией на свою Я-концепцию.

\section{СПИСОК ЛИТЕРАТУРЫ}

1. Ананьев Б.Г. Человек как предмет познания. СПб.: Питер, 2010. 282 с.

2. Андреева Г.М. Психология социального познания. М.: Аспект Пресс, 2009. 303 с.

3. Барабанщиков В.А. Психология восприятия. Организация и развитие перцептивного процесса. М.: КогитоЦентр, 2006. 239 с.

4. Белик А.А. Теория «Я» Дж. Г. Мида и психологическая антропология // Социальная психология и общество. 2011. № 1. С. 31-43.

5. Гусева С.И. Образ математически одаренного ученика в сознании педагога: автореф. дис. на соиск. учен. степ. канд. психол. наук. 19.00.07 / Ленинградский гос. обл. ун-т им. А.С. Пушкина. СПб., 2000. 18 с.

6. Карвасарский Б.Д. Психотерапия. СПб.: Питер, 2002. 672 с.

7. Психология подростка. Полное руководство / под ред. чл.-корр. РАО А.А. Реана. СПб.: Прайм-Еврознак, 2003. $432 \mathrm{c}$.

8. Радина Н.К., Павлычева Т.Н. «Значимые другие» в историях жизни выпускников интернатных сиротских учреждений // Социальная психология и общество. 2010. № 1. С. 124-135.

9. Ситников В.Л. Образ ребенка в сознании детей и взрослых. СПб.: Химиздат, 2001. 288 с.

10. Ситников В.Л. Социально-перцептивные образы и Я-, Ты-концепция // Развитие психологии в системе комплексного человекознания. Часть 2. М.: Изд-во «Институт психологии РАН», 2012. 696 с. С. $382-385$.

11. Спиваковская А.С. Психологическая помощь семьям, взявшим на воспитание детей из государственных учреждений // Лишенные родительского попечительства: хрестоматия. М.: Просвещение, 1991. С. $127-132$.

12. Стреленко А.А. Проблемы психологической безопасности детей и подростков в семейной среде // Психология семьи в современном мире: сб. материалов междунар. науч.-практ. конф. / Урал. гос. пед. ун-т. Электрон. дан. Екатеринбург: [б. и.], 2017. 1 электрон. опт. диск (CD-ROM).

13. Стреленко А.А. Социально-перцептивные образы виктимной личности. Витебск, 2009. 138 с.

14. Шульга Т.И., Антипина М.А. Эмоциональная среда замещающей семьи, принявшей на воспитание подростков, оставшихся без попечения родителей // Психологическая наука и образование. 2018. Т. 23, № 5. С. 51-66. URL: https://doi.org/10.17759/pse.2018230506 (дата обращения: 02.03.2021).

15. Balestra F. Negotiating Selves and Identities in Interaction: between Theory and Methodology // Cultural-Historical Psychology. 2012. Vol. 8, no. 1. P. 47-50.

16. Bergsund H.B. Wentzel-Larsen T., Jacobsen H. Parenting stress in long-term foster carers: A longitudinal study // Child \& Family Social Work. 2020. Vol. 25 (S1). P. 53-62. URL: https://doi.org/10.1111/cfs.12713 (дата обращения: 02.02.2021).

17. Dalgaard N.T., Pontoppidan M., Thomsen M.K., Viinholt B.C.A., Filges T. PROTOCOL: Parenting interventions to support parent/child attachment and psychosocial adjustment in foster and adoptive parents and children: A systematic review // Campbell Syst Rev, 2020. Vol. 16, no. 1 e1072. P. 1-18. URL: https://doi.org/10.1002/cl2.1072 (дата обращения: 14.04.2021). 
18. Shuker L., Sebba J., Höjer I. Teenagers in foster care: Issues, themes, and debates from and for practice and policy // Child \& Family Social Work, 2019. Vol. 24, no. 3. P. 349-353. URL: https://doi.org/10.1111/cfs.12650 (дата обращения: 15.04.2021).

Поступила в редакцию 18.10.2021

Стреленко Анна Анатольевна, кандидат психологических наук, доцент, доцент кафедры психологии Витебский государственный университет имени П.М. Машерова 210038, Республика Беларусь, г. Витебск, Московский проспект, 33 E-mail: strelenko@list.ru

\section{A.A. Strelenko \\ THE STRUCTURE AND CONTENT OF SOCIAL PERCEPTION IMAGES IN THE CONSCIOUS OF FOSTER MOTHERS}

DOI: $10.35634 / 2412-9550-2021-31-4-416-427$

This article examines the problem of the image of a foster child in the representations of foster mothers. The goal of the work is to determine the structural features of the foster mother's I-image, the You-image of the foster child. Research hypothesis - the structure and content of I-images and images of foster children are statistically and qualitatively related. Study participants were 78 people, foster mothers aged 29-66 years $(\mathrm{M}=49,64 ; \mathrm{SD}=7,54)$. Based on the results of the empirical study, structural and content features were revealed in the ideas of foster mothers about themselves and their foster children. There are differences in the components of images: social intelligence $(p \leq 0,05)$, behavioral $(p \leq 0,05)$, bodily $(p \leq 0,05)$, neutral $(p \leq 0.05)$, negative $(p \leq 0,05)$. Correlations were established between the characteristics of the images reflecting attitudes toward a person. Comparison of social-perceptual images in structure and content indicates the similarity of the I-images of mothers with the You-images of their foster children. The results obtained are based on a single mechanism for the development of socio-perceptual images. Foster mothers choose a child and build interaction with him/her, relying not so much on the reflection of real personal features of the child, as on their own ideas about themselves, on their I-concept.

Keywords: I-concept, I-image, You-image, foster mother, foster child, foster family.

Received 18.10.2021

Strelenko A.A., Candidate of Psychology, Associate Professor, Associate Professor at Department of Psychology Vitebsk State University named after P.M. Masherov

Moskovskiy prosp., 33, Vitebsk, Republic of Belarus, 210038

E-mail: strelenko@list.ru 